\title{
The importance of trusting beliefs linked to the corporate website for diffusion of recruiting-related online innovations
}

\author{
María Bermúdez-Edo • Nuria Hurtado-Torres • \\ Juan Alberto Aragón-Correa
}

Published online: 2 October 2010

(C) The Author(s) 2010. This article is published with open access at Springerlink.com

\begin{abstract}
Recruiting-related online innovations represent growing and high-potential opportunities for employers to broaden the reach of their recruiting efforts as well as reduce costs. The diffusion of innovative approaches for online recruiting, however, may experience bias due to potential employees' lack of trust in firms offering positions online, particularly when the firms are small, operate in a risky industry, or are relatively unknown. We use the theory of reasoned action to propose that users of a corporate website develop trust beliefs with regard to three characteristics of the firm: ability, integrity, and benevolence. We have proposed three hypotheses highlighting the importance of trust generated by the corporate website in potential employees. Our experimental results involved a
\end{abstract}

\footnotetext{
M. Bermúdez-Edo

International Computer Science Institute,

University of California, Berkeley, CA, USA

e-mail: mbe@icsi.berkeley.edu

M. Bermúdez-Edo

Research Group GEDES, School of Computer Science and

Telecommunications, University of Granada, C/Periodista

Daniel Saucedo, s.n., 18071 Granada, Spain

N. Hurtado-Torres $(\bowtie)$

Department of Management, School of Economics and Business, University of Granada, 18071 Granada, Spain

e-mail: nhurtado@ugr.es
}

\section{J. A. Aragón-Correa}

Department of Management, School of Economics and Business, University of Granada, 18071 Granada, Spain

e-mail: jaragon@ugr.es

\section{J. A. Aragón-Correa}

Group for Sustainability and Technology, Swiss Federal Institute of Technology/ETH Zurich, Kreuzplatz 5, 8032 Zürich, Switzerland sample of 218 potential employees. These subjects were offered a consulting position in a fictional firm, which could only be known through its corporate website. Although previous literature has paid marginal attention to the influence of users' beliefs regarding corporate integrity and benevolence, our findings showed that users' perceptions of the corporate website regarding firm integrity and benevolence increased the users' willingness to accept a job at the firm. We propose implications of our results for practitioners and for the literature of trust in online contexts.

Keywords Business process innovations - Corporate website - Diffusion of IT services - Empirical study · Lab experiment · IT adoption · Online recruiting · Trust

\section{Introduction}

Monster.com is currently the world's largest online job search websites. With operating expenses in the range of US $\$ 1.3$ million in 2008 [5], Monster illustrates the emerging importance of suppliers for recruiting-related online services. Additionally, a growing number of firms have developed innovations to move their recruiting processes to an online context with only the support of their own websites. The online recruiting process consists of offering positions via the Internet while attempting to attract applications from the best candidates. Recruiting-related online innovations represent growing and high-potential opportunities for employers to broaden their recruiting efforts as well as reduce costs [42]. It is estimated that $55 \%$ of newly hired employees in the United States in 2006 were already managed from online sources [9], and the number is probably increasing. 
The diffusion of innovative approaches for online recruiting may experience bias, however, due to potential employees' lack of trust in firms offering positions online, particularly when the firms are small, operate in a risky industry, or are relatively unknown. The best candidates usually behave selectively in these contexts, avoiding risks such as lost time spent in filling out recruiting forms, sharing personal details with an unknown organization, or becoming involved in a long or frustrating process with an uncertain aim.

While literature on the adoption and diffusion of technological innovations has widely used the theory of reasoned action (TRA) [13] to propose that users' beliefs influence their behavioral intentions [27, 33, 40, 41], the trust beliefs have received minor attention. The focus thus far has mostly been on e-commerce. We propose that trust beliefs developed by users of a corporate website with regard to three characteristics of the firm-ability, integrity, and benevolence-influence their behavioral intention to accept a job offered online by that firm.

Our research answers calls from the literature to pay specific attention to each of the three characteristics influencing trusting beliefs [55]. Trust literature has been traditionally focused on the influence of perceived technical ability and integrity in e-commerce [8, 46, 57]. We show that each dimension can play a relevant role. We contribute to the extension of TRA by paying specific attention to the characteristics of the firms influencing trusting beliefs. We are especially innovative in the analysis of the dimension of benevolence.

We also seek to analyze online relationships outside of the commercial sphere of customer-supplier [23, 24]. An innovative context of analysis is also relevant from a theoretical point of view because trust literature especially highlights the importance of paying specific attention to the consequences in the final findings of the research context $[18,50,56]$. Although the importance of online recruiting innovations has undergone scrutiny, we do not know of any previous works analyzing how theoretical models in the literature may be useful in this context [38].

Our work began with intensive interviews, which included eight experts in the field of recruiting. These interviews focused on how to analyze and simulate a real recruiting on line process. Our lab experiment involved 218 master's students because their profiles are widely targeted by online recruiting campaigns. The subjects agreed to participate in a lab experiment in which they were offered a consulting position in a firm that could only be known through its corporate website. Keeping in mind that 90-95\% of firms are small and medium in the United States and Europe, recruiting interaction with unknown firms is quite common when potential employees are looking for a job (especially in an online context in which geographical proximity is not so relevant). This feature also reinforces the appropriate setting of our analysis as suggested by the interviewed experts.

To summarize, we make three contributions to the literature on the diffusion of online innovations. First, we pay extra attention to the trusting beliefs extending the traditionally used TRA and technology acceptance model (TAM) models for the analysis of innovations acceptance. Second, while the vast majority of previous works, analyzing how trusting beliefs influence on online adaptations, have been focused on the trust of online buyers $[6,30,31$, $36,39,60]$, other literature has highlighted the importance of understanding the trust of agents who do not purchase online a firm's products or services [17]. These agents are particularly important because the vast majority of online users are merely retrieving information rather than making purchases [7]. Previous works have already suggested differences between the use of corporate websites for information gathering and for making purchases [7, 51]. Third, research regarding the influence of trusting beliefs on the diffusion of online innovations has paid little attention to the specific implications of the different attributes of the trustee [17]. Our work finds that two attributes receiving less attention in previous literature-integrity and benevolence-show strong potential in the diffusion of recruiting-related online innovations.

This article includes implications of our results for practitioners' purposes. The practical importance of analyzing how trust works in initial job choice decisions is relevant because it significantly affects employees' job satisfaction, organizational commitment, and turnover intentions [2]. Our research also suggests implications for situations in which different agents (e.g., suppliers, local authorities, neighbors, or scholars) often use a corporate website before determining their level of trust in the firm.

The structure of this article is as follows. We will begin with a review of the importance of the trust in online environments focusing on non-commercial decisions such as those related to the job market. Second, we propose our three hypotheses analyzing if the online users' beliefs in the ability, integrity and benevolence of the firm influence their decision to trust when dealing with the decision of accepting a job. Third, we will describe our methodology and results. We conclude with a discussion and assessment of the implications of our findings, and the limitations and implications of this research for research and practice.

\section{The theory of reasoned action and trusting beliefs}

The theory of reasoned action (TRA) views a person's intention to perform a behavior as the immediate determinant of the action; at the same time, a person's beliefs 
are antecedent to behavior intent to adopt and use any system [1]. The literature has widely used TRA to study the adoption of the technological innovations analyzing the relationships between user beliefs and behavioral intention to use the innovations. Based on the TRA, a person's intention is a function of two basic determinants. The first one is a personal factor related to the individual's positive or negative evaluation of performing the behavior ("attitude toward the behavior"). The second determinant of intention is the person's perception of the social pressure put on him to perform or not to perform the behavior in question ("subjective norm"- - which relates to the normative considerations) [1]. Figure 1 illustrates our use of TRA in this research.

The technology acceptance model (TAM) proposed by Davis [10] and Davis et al. [11] derived from TRA has been widely used in explaining the adoption and usage of information technologies (IT) [21, 22, 28, 48, 61, 62]. TAM predicts user acceptance of any technology to be determined by two factors: perceived usefulness and perceived ease of use.

TRA and TAM are both built on the assumption that human beings are normally quite rational and make systematic use of the information available to them; however, TRA and TAM might have more difficulties explaining decisions of trust in risky interactions with anonymous organizations. Trusting belief is the individual belief (not necessarily rationally founded) that the trustee has characteristics that would benefit the trustor [43]. These beliefs lead to trusting intention, which is the willingness or intention of the trustor to rely on the trustee. Finally, trusting intention leads to trusting behavior, which is the act of the trustor becoming vulnerable to the trustee in a situation of uncertainty. This cognitive process of trust formation has been shown to positively influence a person's intention to use e-commerce websites [19, 20, 44, 63].

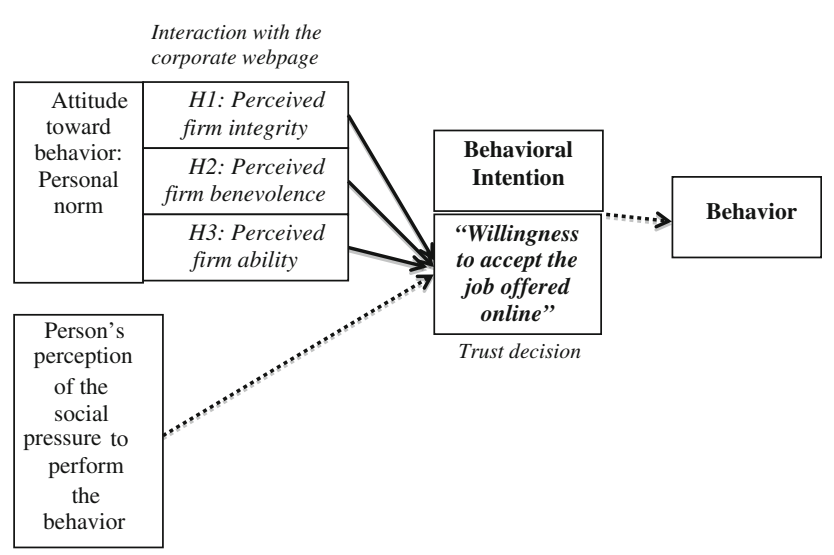

Fig. 1 The theory of research action and its application to our analysis
Hence, trust implies the willingness to be vulnerable based upon positive expectations of the behavior of another under conditions of risk and interdependence [52]. Three characteristics of the trustee have been analyzed as relevant to influence consumer trust in the usage of e-commerce: ability, integrity, and benevolence [45]. Ability means the potential of providing a quality output in time; integrity suggests that the firm will fulfill agreements as promised; and benevolence means a strong desire to serve buyer's needs aside from an egocentric profit motive [55]. Although these three dimensions have been accepted as important in the literature of e-commerce acceptance, ability has received much attention; the others, integrity and benevolence, have been accepted as marginal or aggregated [55]. Relevant literature has called for extending the disaggregated analysis of the three dimensions and analyzing it outside of commercial environments [23, 24].

These two remaining issues are relevant since information supplied by the corporate websites has exponentially grown in the last years, including a wide range of non-commercial aspects. Most firms have a corporate website, and it usually offers a broad range of information, such as the mission statement, strategic objectives, functional details, customers' profiles, history, and financial information, among other features. All these online capabilities developed by the firms to build their corporate website look well suited to engage the different stakeholders when the firm is dealing with emerging technologies [3]. Additionally, the trust literature has highlighted that different contexts may raise theoretical concerns regarding implications of each trust dimension $[14,50,56]$.

The job choice process begins with an individual's evaluation of information obtained from recruiting sources [15]. Although it is well known that the image of an organization affects the initial decisions of potential applicants, it is still unknown how candidates' beliefs affect theirs decisions $[15,53]$. The importance of corporate sources of information [26] may be easily accepted as greater for the development of initial trust [35], especially when the candidate lacks prior knowledge of the firm as common in the online context.

Potential employees may require corporate information before making the decision to work in the firm; even so, they will probably want to check the corporate website to reinforce or modify their previous beliefs. However, globalization, the lack of geographical proximity, and the invisibility of many firms to media (especially those of small or medium size) often imply the absence of previous interaction between potential candidates and the firm. This underscores a maximum level of importance for the website of the firm.

Some authors have suggested that the Internet has revolutionized how people search for jobs [4]. Corporate 
websites are one of the most used sources to attract employees. Data show that all Fortune 100 companies and $94 \%$ of all global companies use their websites for recruiting [25, 39, 42]. Although the literature has offered descriptive evidence to suggest the importance of reinforcing this process using marketing tools [42] or a perspective of human resource management [49], previous works have failed to provide a model and evidence to explain how these things influence online users whose willingness to work in the firm may be increased [42].

\section{Hypotheses}

We next will discuss our three hypotheses in this work. Figure 1, shown earlier, illustrates our hypotheses. Although a person's perception of social pressure is important to understand behavioral intention, the scope of our research focuses on the three dimensions of trust related to the personal norm and the different relationship of each one with the behavioral intention.

\subsection{The firm's integrity as perceived by the users of the corporate website}

The consistency of the trustee's past actions, credible communications about the trustee from other parties, belief that the trustee has a strong sense of justice, and the extent to which the party's actions are congruent with his words all affect the degree to which the firm is judged to have integrity [43]. The literature on trust in online environments has focused on the buyers' concern regarding whether sellers will act opportunistically by not delivering the products [17]. However, when dealing with products or services which are not completely defined in advance, such as a hotel room, a tailored suit, or a job, online buyers are mostly concerned about inferring product quality and characteristics and buyers' trust in sellers is focused on product misrepresentation due to lack of seller integrity [17]. For instance, perceptions of the firm's integrity increase trust when deciding on a web-based recommendation agent because the customer believes that relying on the recommendation agents will provide truthful and objective recommendations [34].

The willingness to accept a job implies that a trustee believes the firm will completely fulfill the promised conditions of employment. In the context of accepting a job when firm information is mainly coming from the corporate website, the firm's integrity as perceived by the online users will mean that the user believes that the firm is providing an objective panorama regarding the post and the firm. For instance, users assume that there is no hidden information about duties, salary, or activities.
Psychological implications of the integrity (versus more technically based roots of the firm's ability) might make more difficult the opportunities to reinforce the perceptions of the firm's integrity using online information. Different alternatives might help to reinforce the online perception of integrity in this context, such as: the joint efforts of the firm with non-governmental organizations, voluntary collaborations with local authorities, or the support of prestigious customers, experts. If the online users perceive firm integrity, they will reduce the feeling of potential frauds when trusting in the firm. Thus, we assert:

Hypothesis 1 (Firm Integrity Hypothesis): Increased firm integrity perceived by the users of the corporate website will increase their willingness to accept a job in the firm.

\subsection{The firm's benevolence perceived by the users} of the corporate website

Benevolence is the extent to which a trustee is believed to want to do well on behalf of the trustor, aside from an egocentric profit motive [43]. In other words, benevolence is the perception that the trustee intends to act in the trustor's interest [45], even if there is no extrinsic reward for the trustee. Trust emerges when trustors perceive trustees to be genuinely interested in the trustor's welfare and is motivated to seek joint gain [12].

Early works proposed benevolence as a basis for trust [37]. However, benevolence has received little attention in the trust literature [55] and is particularly scarce in the literature on trust in online environments [17]. A few works have shown the potential of benevolence in some specific online environments. For instance, Pavlou and Dimoka [50] showed that benevolence has a stronger effect on price premiums than on ability and credibility (what we call integrity in our work) in online auction marketplaces.

In the context of accepting a job when firm information is mainly coming from the corporate website, the extent of a firm's benevolence perceived by online users will mean that the user believes that relying on the firm will provide an appropriate environment for the multiple situations in which an explicit commitment was not made [14]. These kind of situations may occur more often in an employment relationship because of the importance of discretional decisions regarding promotions, international mobility, sick or family leaves, or bonuses.

The lack of previous interactions with the firm makes the users' belief linked to the corporate website particularly important. The employment relationships involve some communal relationships in which identification with the other is particularly important, whereas completely marketbased exchanges (e.g., e-commerce) may emphasize 
rational calculus, where characteristics of interactions are based upon economic exchange [52]. Explicit consideration of such things as codes of conduct, employment policies, or description of positive experiences represent some of the online characteristics that might be useful to determine the trustee's beliefs regarding firm's benevolence. Thus, we will test:

Hypothesis 2 (Firm Benevolence Hypothesis): Increased firm benevolence perceived by the users of the corporate website will increase their willingness to accept a job in the firm.

\subsection{The firm's ability perceived by the users of the corporate website}

Trustors must determine that trustees are capable of meeting their obligations and the trustor's expectations, assuming that trustees differ significantly in their competence to deliver on their promises [12]. In a more descriptive way, ability is that group of skills, competencies and characteristics that enable a party to have influence within a specific domain [43]. Multiple works have analyzed similar constructs based on the perceptions of the technical competence and, for instance, trust in the industrial salespeople increases as the customer gains the impression that the salesperson is dependable and competent [59].

The literature on trust in online environments has shown that users' beliefs regarding a firm's ability are a primary requirement for e-commerce. These beliefs affect the intentions to inquire about products, although it does not mean that the user will purchase the product [18]. The addition of ability to the antecedents of trust creates a framework of trust that is domain-specific [12]. Hence, it is important to examine the characteristics of each specific situation because abilities to trust a firm are different for different decisions. For instance, trusting beliefs in the firm's ability increase when a web-based recommendation agent suggests a specific product or service. This because the customer feels that the recommendation agent will generate well-customized recommendations [34].

In the context of accepting a job when firm information is mainly coming from the corporate website, the firm's ability, as perceived by online users, will mean that the user believes that relying on the firm will provide an appropriate environment for their professional development. In our experience, the firm's ability to offer successful development is usually linked to positive outcomes for the employee, such as the existence of attractive products or processes, the availability of resources for exploring innovative ways, or the opportunities of reinforcing their own vita with a working experience in a prestigious firm.
Although the users of corporate online information do not have direct experience with the intrinsic quality of resources, products, services or processes in the firm, users may generate a trustee's beliefs regarding firm ability after scanning specific issues perceived to be proxies for the firm's competence. These issues may include the number of employees or its financial size, its locations, descriptions of the products or processes of the firm, financial information about the firm, or customer profiles, among others. Thus, we state our third hypothesis:

Hypothesis 3 (Firm Ability Hypothesis): Increased firm ability perceived by the users of the corporate website will increase their willingness to accept a job in the firm.

\section{Methodology}

\subsection{Participants and experimental procedures}

We used a series of intensive interviews with eight experts in the processes of recruiting to make our methodology effective. They include: three respondents who were working in consulting firms, three others who were directors of human resource management, and finally two university scholars). We also followed several online debates regarding the potential of online recruiting. One was from The Economist, which conducted an online debate in September 2009 involving different professional views. This enabled us to better understand the complexity of the problem. Finally, our own experience in the field of IT consulting and innovation research has provided relevant input in the design of the methodology. In this section, we detail the design and procedures that we used to test these hypotheses.

After our detailed review of multiple corporate websites in the industry, we built a corporate website for a fictional firm, using a model for the corporate website provided by an intermediary firm in the sector. Our selection was intended to be as representative as possible of the majority of firms in the industry.

We recruited 218 subjects attending business courses at the master's level of a large public university in Europe. The selection is appropriate because this profile is one of the most targeted by online campaigns of recruiting. Additionally the lab experiment is appropriate because it allows us to focus on the potential influence of specific variables that we included in the analysis. As is usual in lab experiments, we asked for our subjects' formal written agreement to participate in the experiment in advance. To motivate the participants to view the lab experiment as a real situation, they were told before the experiment that one participant would receive $€ 200$ and that all of the 
participants would get extra credit in their business courses. All experimental sessions were conducted in the same computer laboratories. The participants were told not to talk to anyone, and they worked in individual cubicles under the supervision of the authors and our assistants.

After reading the instructions, subjects completed a prequestionnaire on their socio-demographic characteristics, Internet experience, general trust in the Internet and firms, and interest in different socio-economic issues. This information was compiled to control for other potential influences.

We then distributed a document with information about the experimental situation. Each subject was offered a consulting position in a chemical firm. The text mentioned general details about the duties involved and offered the subject an opportunity to analyze additional information of the firm through its corporate website. Participants were randomly assigned to one of two groups. The situations described for each group were the same, except that one description emphasized the business uncertainty of the chemical industry. This treatment was provided to check the attention of the users to instructions. We included the same number of participants in each group to avoid bias in the results. This document was retained by the subjects and could be read during the time that they filled out the subsequent questionnaire.

The corporate website that we designed was always available for participants in the lab experiment. The participants were asked to give answers assuming that the firm and its open position were real, but its fictional nature was important to avoid any previous interaction with the firm by participants.

Each participant participated in the experiment individually and was allowed to take as much time as needed. We checked that all of them were using the corporate website before answering the online questionnaires. Our analysis concerning the subjects' perceptions about the firm's ability, integrity and benevolence and the willingness to accept a job in the firm is based on their responses to questions in these instruments. As in real life, it was always possible to come back to the corporate website before the subject answered any questions that we asked them.

Participants spent between 25 and 32 min for the whole experiment. Two participants were eliminated in the final sample for lack of attention to the task: they gave answers to the entire questionnaire using only 15 and $18 \mathrm{~min}$ for each one. The online questionnaire did not accept missing data; all its questions had to be answered. The final sample remaining included 218 responses.

\subsection{Measures}

Scales to measure each of the constructs in the model were developed based on the previous literature, and existing scales were used where possible. The subjects' answers showed a reasonable dispersion in their distributions across the ranges. Seven-point Likert scales were used for all survey items, ranging from "Total Disagreement" to "Total Agreement." We selected and adapted various items from Gefen [16] because of his detailed verification of the scales' validity, reliability and his similar effort to study ability, integrity and benevolence [50]. These scales are closely linked with our research and with our definitions of the constructs of integrity, ability and benevolence. The items and descriptive statistics (see Table 3) are included in Appendix 1 at the end of this article.

\subsubsection{Integrity}

Several studies have developed scales to measure and evaluate integrity, we used five adapted items from Gefen [16], and asked to subjects to express their belief on the honesty of the experimental firm. We developed a confirmatory factor analysis to validate our scales $\left(\chi^{2}=5.89\right.$ with 5 d.f., $\mathrm{RMSEA}=0.02$, GFI $=1.00$, AGFI $=0.99$, $\mathrm{CN}=556.90)$ and showed that the scale was one-dimensional and had a high reliability, with Cronbach's $\alpha=$.894. Although the recommendations of the literature differ, there is a consensus that values of Cronbach's $\alpha$ of around 0.8 constitute acceptable or sufficient reliability.

\subsubsection{Benevolence}

Although the literature has paid minor attention to the measurement of benevolence, we selected and adapted various items from Gefen's scale [16]. We used five items and asked subjects to express their level of agreement or disagreement with the intentions of the experimental firm to do well, aside from wanting to make a legitimate profit. We developed a confirmatory factor analysis to validate our scales $\left(\chi^{2}=7.59\right.$ with 5 d.f., $\mathrm{RMSEA}=0.06$, $\mathrm{GFI}=0.99, \mathrm{AGFI}=0.98, \mathrm{CN}=432.26)$ and showed that the scale was one-dimensional and had a high reliability, with Cronbach's $\alpha=.781$.

\subsubsection{Ability}

In this research, we developed five items also drawing on a scale used by Gefen [16]. We asked subjects to express their level of agreement or disagreement with the existence of different abilities in the firm. We developed a confirmatory factor analysis to validate our scales $\left(\chi^{2}=1.62\right.$ with 4 d.f., $\mathrm{RMSEA}=0.0, \mathrm{GFI}=1.00, \mathrm{AGFI}=1.00$, $\mathrm{CN}=1,778.24)$. The process of validation rejected the inclusion of the item Ability 3 in the final scale and showed that the final scale was one-dimensional and had a high reliability, with Cronbach's $\alpha=.766$. 


\subsubsection{Willingness to accept the job}

Previous literature usually refers to the intentions to accept vulnerability in e-commerce situations [31]. Schoorman et al. [55] have used the term trusting intentions to mean the trust that employees have in their general manager. In our study, three items were used to measure the trust determined as the related intention of accepting the job: professional willingness to accept the job, personal willingness to accept the job, and global willingness to accept the job. We used the three items and asked the subjects to express their level of agreement or disagreement. We used an arithmetic mean of the three answers for our final measurement. Cronbach's $\alpha=0.836$ for this scale.

\subsubsection{Control variables}

The prior literature about online environments has shown there are multiple factors influencing the trusting intentions. These include factors related to the characteristics of the websites as well as individual differences among the participants [58]. We controlled for several factors in this research. As the socio-demographics features of the participants were similar and only one website was used, we controlled for the potential effects of propensity to trust websites and for propensity to trust firms. We used three items for each variable, all of them directly obtained from Stewart [58]. These control variables fit with the trust literature, suggesting that propensity may be an important factor to decide trust in a target [44]. Cronbach's $\alpha=.781$ for the scales representing the propensity to trust websites construct and $\alpha=.781$ for the propensity to trust firms construct.

\section{Results}

Table 1 shows the means, standard deviations and correlation between the variables analyzed. Table 2 offers the results of the regression analysis [29] and the estimated coefficients of the different models. In Appendix 2, we are including the scatterplot graphics for the regressions showing visually the inclusion of our cases in a confident interval of the $95 \%$.

Table 1 Means, standard deviation, and correlation

\begin{tabular}{lllllllll}
\hline & Variable & Mean & S.D. & 1 & 2 & 3 & 4 & 5 \\
\hline 1 & Willingness to accept the job (trust) & 4.94 & .98 & - & & & \\
2 & Propensity to trust websites & 4.21 & .79 & $.36^{* * *}$ & - & & \\
3 & Propensity to trust firms & 4.11 & .77 & $.40^{* * *}$ & $.68^{* * *}$ & - & & \\
4 & Perceived integrity & 4.57 & .95 & $.49^{* * *}$ & $.39^{* * *}$ & $.41^{* * *}$ & - \\
5 & Perceived benevolence & 4.14 & .84 & $.52^{* * *}$ & $.28^{* * *}$ & $.29^{* * *}$ & $.55^{* * *}-$ \\
6 & Perceived ability & 5.32 & .71 & $.35^{* *}$ & $.27^{* *}$ & $.38^{* *}$ & $.56^{* *}$ & $.34^{* *}$ \\
\hline
\end{tabular}

$N=218$ for all variables

Significance levels: $* p<.10, * * p<.05, * * * p<.01$

Table 2 Results of the multiple regression analysis

\begin{tabular}{|c|c|c|c|c|}
\hline Variable & Model 1 & Model 2 & Model 3 & Model 4 \\
\hline Constant & $2.591 * * *(.356)$ & $1.731 * *(.360)$ & $1.090 * *(.363)$ & $.899 * *(.458)$ \\
\hline Propensity to trust website & $.196 *(.104)$ & $.103(.098)$ & $.079(.093)$ & $.084(.093)$ \\
\hline Propensity to trust firm & $.372 * * *(.108)$ & $.240 * *(.102)$ & $.224 * *(.097)$ & $.210 * *(.099)$ \\
\hline Integrity & & $.393 * * *(.066)$ & $.219 * *(.071)$ & $.195 * *(.079)$ \\
\hline Benevolence & & & $.387 * * *(.076)$ & $.386 * * *(.076)$ \\
\hline Ability & & & & $.064(.093)$ \\
\hline$F$ & $22.92 * * *$ & $29.75 * * *$ & $31.40 * * *$ & $25.152 * * *$ \\
\hline$R^{2}$ & .176 & .294 & .371 & .372 \\
\hline Change in $R^{2}$ & & .119 & .077 & .001 \\
\hline
\end{tabular}

Willingness to accept the job, a proxy for trust, is the dependent variable. The values correspond to the non-standardiz-ed regression coefficients, with the typical standard error in parentheses

Significance levels: $* p<.10, * * p<.05$, *** $p<.01$ 
The control variables are included in the first model in Table 2. For the equation including the control variables, the results indicate that $17.6 \%$ of the variance in willingness to accept the job was explained by a propensity to trust websites and a propensity to trust firms. In the second model, we introduced the users' beliefs regarding firm integrity, which contributed significantly to improved the fit. An additional $11.9 \%$ of the variance was explained by users' beliefs regarding firm integrity. Our results supported the Firm Integrity Hypothesis (H1) $(p<0.01)$. For the subjects in our sample, there is a positive relationship between firm integrity perceived by the users of the corporate website and their willingness to accept a job.

In the third model, we added the direct effect of the benevolence, which contributed significantly to improve our results. The Firm Benevolence Hypothesis (H2) was also supported $(p<0.01)$. This indicated a positive relationship between firm benevolence perceived by the users of the corporate website and their willingness to accept a job. Finally, the fourth model includes the effects of the users' belief regarding firm ability. The Firm Ability Hypothesis (H3), which postulated a positive relationship between firm ability perceived by the users of the corporate website and their willingness to accept a job, was not supported. Multicollinearity was not observed as a problem, since the tolerance indices and variance inflation factors for each regression model were at acceptable values. Variance inflation factor values were all within the acceptable range, with values less than 5 .

Regarding our control variables, propensity to trust firms showed a positive and significant influence in all the models that we analyzed. However, propensity to trust the website did not show a significant influence for our context when other variables were integrated in the analysis. As we expected, there were no significant differences between the groups with or without uncertainty of the chemical industry, in terms of their answers to the pre-questionnaire. There were different perceptions about the uncertainty of the situation in a control analysis following the presentation of the informational document though.

\section{Conclusion}

Our results are consistent with the theory of reasoned action (TRA), which asserts that beliefs positively affect attitude [13]. More specifically, our results agree with prior research showing that trusting beliefs positively affect trusting intentions [55] and with literature stating the specific influence of the three dimensions of trusting beliefs in the online environments [37]: ability, integrity and benevolence. Our model offers a useful theoretical approach to better understand innovation-related needs that are associated with the diffusion of new IT services. Psychological, technological, and business effects appear here as joint determinants of the diffusion and effects of IT services. This approach also answers the special issue editors' call for a "broader umbrella" of theory, by accounting for different dimensions related to the diffusion of technological innovations.

\subsection{Discussion}

\subsubsection{Research implications}

While prior research with online customers has already stated the importance of the three dimensions of trustworthiness, limited attention has been paid to understand how different users of corporate websites generate trust in the firm and the specific influence of each trusting dimension [17]. In addition, while previous literature has highlighted the importance of a firm's ability and integrity, our work complements previous findings, showing the positive influence of the beliefs of online users regarding firm integrity and benevolence on the willingness to accept a job in the firm.

Moreover, our work illustrates the use of lab experiments as appropriate methods that can address research questions in the diffusion of IT services. The potential of this methodology to generate a real and properly controlled background offers appealing opportunities to better understand situations with difficult visibility in a different context. For example, online users' perception of integrity or benevolence may be specifically measured; thus, we can better define their implications for the action.

Our methodology allows us to complement previous findings in e-commerce literature. While the previous literature has widely shown the importance of user beliefs regarding technical ability, our results showed a significant impact of benevolence and integrity. However, ability was not statistically significant for our context. Although we do not have enough evidence to nail down the differences between our hypothesis and our results with full explanations, we can suggest a potential explanation. The level and the influence of various dimensions of trusting beliefs may be contingent on the different context of our study in comparison with the contexts used in the work of others. The specific stage of the generation of trust in the online context, the different implications of the decisions, and the unique profiles of the online users all serve as relevant factors.

\subsubsection{Alternative theoretical explanations}

We propose three other ways to explain these differences, and all of them should be tested in the future to improve our theoretical understanding of the key relationships in 
our study context. First, we believe that although the perception of the firm's ability may be a prerequisite for the subsequent steps, integrity and benevolence may be the determinants for a subject's final intention to trust the firm. Our experimental setting does not allow us to check this possibility though. So future research might analyze how, if levels of perceived ability are not enough, that ability alone might determine that the online users do not trust in the firm. However, when perceived ability is enough, this dimension may not guarantee the trust in the firm.

Second, we suggest that benevolence might be particularly important in situations where an identification with the firm over time is particularly necessary, and where completely regulation-based exchanges are not possible. For instance, there are employment relationships in which the candidate cannot be provided with a dependable environment for future promotion, where there are potential risks of changes in specific conditions like business hours, or where there is a friendly organizational culture. However, ability and more rational planning might be more important for a single market-based exchange [52]. The majority of the e-commerce situations match this situation well, especially when the risks involved are low and the product is well known. For instance, it is more difficult to understand how benevolence might be important to decide a consumer's final trust in a firm for buying a book or a CD. However, perceptions of a firm's ability and integrity might be the most relevant in situations in which the relationships are based upon less tangible features.

Finally, trust is likely to form via a capability process in societies where people perceive a large competence gap and show respect for individual qualifications, expertise, and accomplishment [12]. Since our sample focused on a subset of well-educated people, especially in those fields related to management, this profile of online users could generate a narrower appraisal of the connection between ability and trust.

\subsubsection{Practical implications}

Our findings have also some practical implications. The World Economic Forum reported that the overall trust level for companies in 2006 had been the lowest since they began this analysis in 2003 [55], and the situation may be even worse after the world financial crisis at the beginning of the twenty-first century. Additionally, the specific problems of trust for online contexts might still increase these tensions. Our results suggest a better understanding of websites as a "sensory emotive space where we are able to move the web from an emotionally flat environment to a space of rich interactions" [32]. In this context, managers might want to utilize specific observations from our work. We include some of the more salient ones below.
The huge potential of the Internet for offering detailed information and tailored communications to users appears to be a relevant influence on stakeholder trust. The corporate website should facilitate the delivery of customized content for consumers [54], but also should reflect the unique needs and individual preferences of other kinds of stakeholders. Our study illustrates how the potential to generate a high willingness to work in the firm is strongly dependent on its capabilities to generate candidates' trust on perceptions about the firm's behavior through its corporate website. Managers should try to answer online a complete set of general and specific information about their corporation's behavior and intentions. This information should consider the multiple situations in which online users may want to examine the corporate website to support final decisions about whether a user will trust the firm. It is important to keep in mind that diffusion of company information through new technologies such as corporate webpages reinforces the interest of multiple and differentiated stakeholders in the firm. These include customers, suppliers, investors, industry experts, jobs seekers, scholars, green activists or neighbors, among others.

Corporate websites usually focus on technical features, such as the products and processes in the firm or on financial details. However, our results show the importance of paying specific attention to factors with the potential to generate greater feelings of integrity and benevolence among corporate website users. Social networks and the diffusion of technology innovations that support online interactions and multimedia may be especially useful for firms to increase market perceptions of their integrity and their benevolence. Real employees or customers may offer more appealing testimonials than the corporate press services for multiple stakeholders. It is important to note that corporate information available online influences the confidence of stakeholders and affects how different dimensions of trust may be important to build that trust.

\subsection{Limitations and future research}

\subsubsection{Limitations}

As in any empirical analysis, our research has limitations. The lab experiment was carried out using participants from the university student population who were young and well-educated, but who had limited experience in the job market. These specific characteristics reduce the potential of the universal applicability of our results, since many corporate recruiting websites are targeted to industry professionals. However, the decisions of accepting jobs for consulting firms are often associated with a population that is similar to what we have in our sample. Hence, the sample that we analyzed fits well with the problem as it is 
normally encountered in the real world, and so it reinforces the strength of our analysis.

Despite the study's limitations, this article is one of the first specific analyses of the effects on the relevance of the trustworthiness beliefs-ability, credibility, and benevolence-in the online environments. The current research has focused on the connection between a set of factors related to trustworthiness beliefs, and an applicant's willingness to accept a job. It fits well with our objective in this research. Our research will benefit from the consideration of additional factors influencing the evolution of the willingness to accept the job offered online. The inclusion of additional variables would be useful for a better understanding of the final evolution of the dependent variable and increasing the variance explained by the regression. Additionally, our analysis uses a non-commercial situation involving the willingness of an applicant to accept a job in the firm in order to show the relevance of our arguments in the most common situation of the online environments, when online users gather information in the websites helping to delimitate their trusting beliefs.

\subsubsection{Future research}

Our research can be extended in multiple directions. First, it will be appropriate to reinforce the attention paid to research that has analyzed technical approaches that allow managers to determine and continually optimize the corporate website according to the specific corporate business processes and objectives [47]. Second, our hypotheses should be tested and compared with those for other situations that do not involve the acceptance of a job. Different environmental situations might also generate situations in which trustworthiness beliefs vary in their influence on trust. In any case, our lab results are specific to our sample population. So further testing of our hypotheses will be useful with other types of populations and other methods. Third, our study explores initial trust, but influences on trusting beliefs might be different over time. For instance, the contingent effect of the general business environment on the dynamics of trust may be of particular importance in mature industries. Finally, the effects of mistrust might be also an attractive topic. The growing potential of social networks on the Internet may reinforce the importance of unsatisfactory experiences with the firm.

Acknowledgments This work has been partially funded by the Spanish Ministry of Education (project SEJ2007-67833) and the Andalusian Regional Government (Excelence Research Project P06SEJ-2356).

Open Access This article is distributed under the terms of the Creative Commons Attribution Noncommercial License which permits any noncommercial use, distribution, and reproduction in any medium, provided the original author(s) and source are credited.
Appendix 1: Items for the analyzed variables and descriptive statistics

Ability items:

1. I believe that $\mathrm{A}$ is a company with high technical capabilities in the environmental field (Ability 1).

2. I believe that firm A understands perfectly the environmental problems of the industry it works, and how to solve them (Ability 2).

3. I believe that firm A understands quite well the environmental problems of its products and knows how to solve them (Ability 3).

4. I believe that firm A has excellent resources to accomplish its environmental obligations (Ability 4).

5. I believe that the approaches of the managers of the firm A are really accurate for a good environmental management (Ability 5).

Integrity items:

1. I believe that firm A will meet its environmental commitments as described in its website (Integrity 1).

2. I believe that firm A is doing the advance environmental processes that are described in its website (Integrity 2).

3. I believe A's environmental commitments deserve confidence (Integrity 3).

4. I believe that the environmental commitments of the firm A are credible (Integrity 4).

5. I think that A's commitment to develop environmental improvements is sincere (Integrity 5).

Benevolence items:

1. I believe that if there was any environmental problem, A will be willing to guarantee my health even if it would endanger his reputation (Benevolence 1).

2. I believe that A would even be willing to make economic sacrifices if needed to ensure my safety environment (Benevolence 2).

3. I believe that A would not act opportunistically in environmental issues; even it has the chance to do it (Benevolence 3).

4. I believe that A will take into account my environmental concerns anytime (Benevolence 4).

5. I believe that $\mathrm{A}$ will continue making significant environmental improvements, even if it has to reduce its benefits to get it (Benevolence 5).

Willingness to accept the job:

1. My global willingness to accept the job in this chemical company is very positive (Willingness 1 ). 
2. I will work for this company without doubts (Willingness 2).

3. I am determined to accept the proposal of my boss to work in this chemical firm (Willingness 3).

Table 3 Descriptive statistics

\begin{tabular}{lllll}
\hline Variables & Mean & $\begin{array}{l}\text { Standard } \\
\text { deviation }\end{array}$ & Minimum & Maximum \\
\hline Willingness 1 & 4.88 & 1.314 & 1 & 7 \\
Willingness 2 & 4.55 & 1.421 & 1 & 7 \\
Willingness 3 & 5.12 & 1.432 & 1 & 7 \\
Integrity 1 & 4.61 & 1.150 & 1 & 7 \\
Integrity 2 & 4.74 & 1.070 & 2 & 7 \\
Integrity 3 & 4.28 & 1.130 & 1 & 7 \\
Integrity 4 & 4.63 & 1.174 & 1 & 7 \\
Integrity 5 & 4.59 & 1.160 & 2 & 7 \\
Ability 1 & 5.44 & 0.90 & 3 & 7 \\
Ability 2 & 5.42 & 0.872 & 3 & 7 \\
Ability 3 & 5.65 & 1.038 & 2 & 7 \\
Ability 4 & 5.10 & 1.011 & 3 & 7 \\
Ability5 & 4.99 & 1.12 & 2 & 7 \\
Benevolence 1 & 4.08 & 1.227 & 1 & 7 \\
Benevolence 2 & 4.08 & 1.160 & 1 & 7 \\
Benevolence 3 & 4.04 & 1.104 & 1 & 7 \\
Benevolence 4 & 4.50 & 1.053 & 2 & 7 \\
Benevolence 5 & 4.01 & 1.211 & 1 & 7 \\
\hline N 218 for al & & 1 & 7 \\
\hline
\end{tabular}

$N=218$ for all of the variables in this table

\section{Appendix 2: Scatterplots}
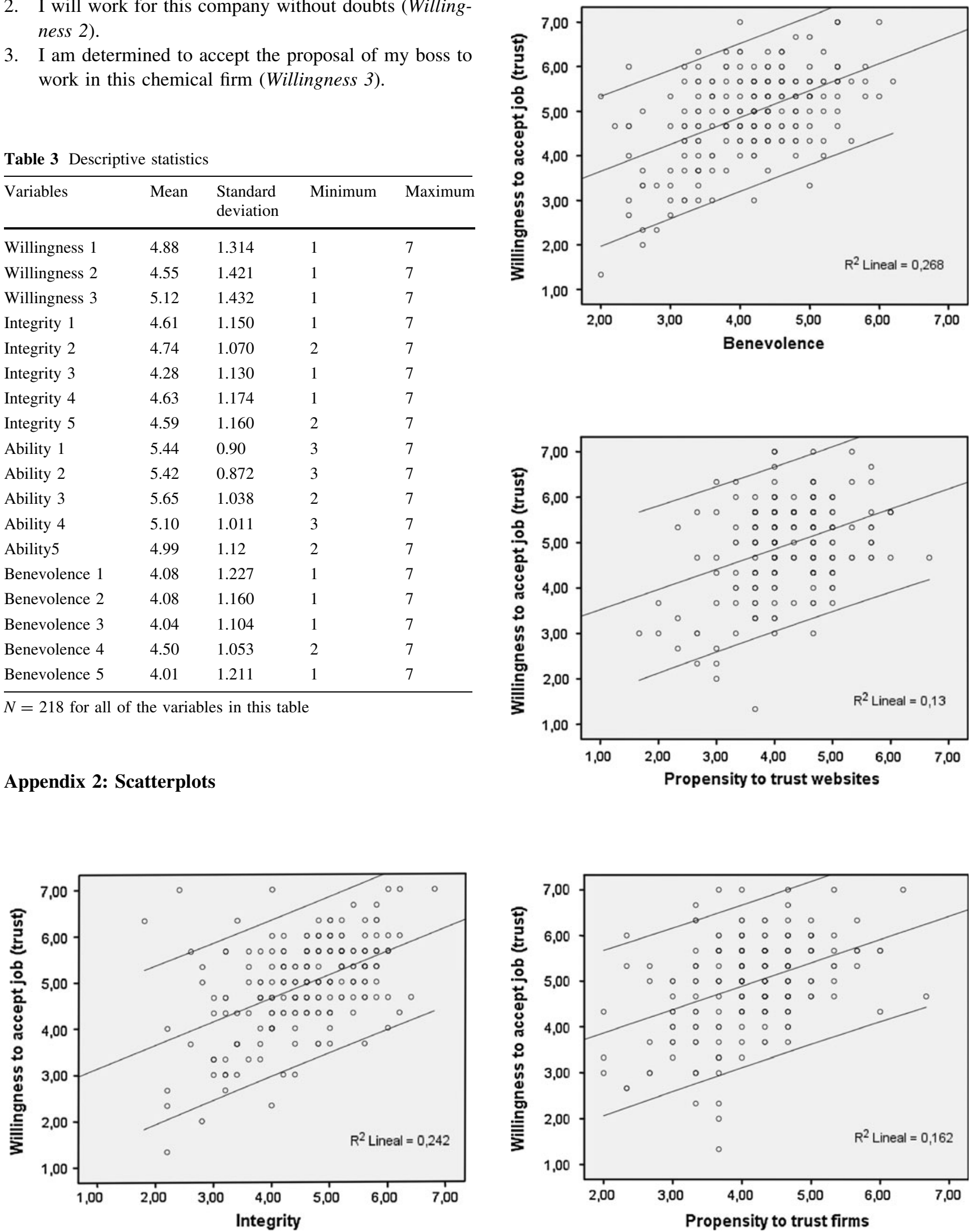


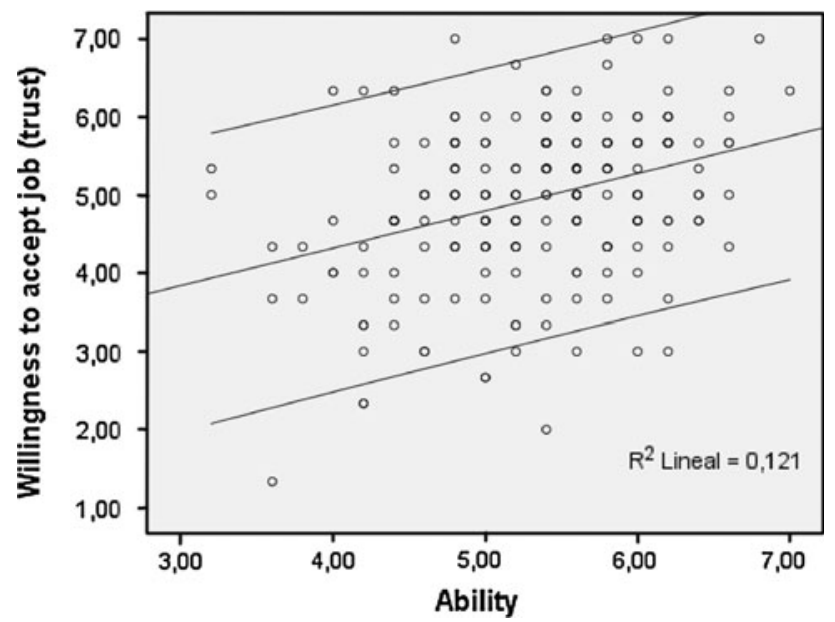

\section{References}

1. Ajzen I, Fishbein M (1980) Understanding attitudes and predicting social behavior. Prentice-Hall, Englewood Cliffs, NJ

2. Alder GS, Noel TW, Ambrose ML (2006) Clarifying the effects of internet monitoring on job attitudes: the mediating role of employee trust. Inf Manag 43(7):894-903

3. Au YA, Kauffman RJ (2008) The economics of mobile payments: understanding stakeholder issues for an emerging financial technology. E Comm Res Appl 7(2):141-167

4. Birchfield D (2002) Top jobs online. N Z Manag 49(8):18

5. BusinessWire (2008) Monster worldwide comments on expectations for first quarter 2008 operating expenses. (March 31). p 553

6. Chen SC, Dhillon GS (2003) Interpreting dimensions of consumer trust in e-commerce. Inf Technol Manag 4(2-3):303-318

7. Choudhury V, Karahanna E (2008) The relative advantage of electronic channels: a multidimensional view. MIS Q 32(1): 179-200

8. Clarke J (2007) Trust, reputation, integrity and professionalism reflections on business relationships. Accountancy Ireland 39(1):54-58

9. Cober RT, Brown DJ (2007) Direct employers association recruiting trends survey. Booz Allen Hamilton, Washington, DC

10. Davis FD (1989) Perceived usefulness, perceived ease of use, and user acceptance of information technology. MIS Q 13(3): 319-339

11. Davis FD, Bagozzi RP, Warshaw PR (1989) User acceptance of computer technology: a comparison of two theoretical models. Manage Sci 35(8):982-1003

12. Doney PM, Cannon JP, Mullen MR (1998) Understanding the influence of national culture on the development of trust. Acad Manage Rev 23(3):601-620

13. Fishbein M, Ajzen I (1975) Belief, attitude, intention and behavior: an introduction to theory and research. Addison Wesley, Reading, MA

14. Ganesan P, García-Molina H, Widom J (2003) Exploiting hierarchical domain structure to compute similarity. ACM Trans Inf Syst 41(4):71-81

15. Gatewood R, Gowan MA, Lautenschlager GJ (1993) Corporate image, recruitment image, and initial job choice decisions. Acad Manage J 36(2):414-427

16. Gefen D (2002) Reflections on the dimensions of trust and trustworthiness among online consumer. ACM SIGMIS Database $33(3): 38-53$
17. Gefen D, Benbasat I, Pavlou PA (2008) A research agenda for trust in online environments. J Manage Inf Syst 24(4):275-286

18. Gefen D, Heart T (2006) On the need to include national culture as a central issue in e-commerce trust beliefs. J Glob Inf Syst 14(4):1-30

19. Gefen D, Karahanna E, Straub DW (2003) Potential and repeat e-consumers: the role of and trust vis-à-vis TAM. IEEE Trans Eng Manag 50(3):307-321

20. Gefen D, Karahanna E, Straub DW (2003) Trust and TAM in online shopping: an integrated model. MIS Q 27(1):51-90

21. Gefen D, Straub DW (1997) Gender differences in the perception and use of e-mail: an extension to the technology acceptance model. MIS Q 21(4):389-400

22. Gefen D, Straub DW (2000) The relative importance of perceived ease of use in IS adoption: a study of e-commerce adoption. J Assoc Inf Syst 1(8):1-30

23. Gill AS (2008) The role of trust in employee-manager relationship. Int J Contemp Hosp Manag 20(1):98-103

24. Gill A, Mathur N (2007) Improving employee dedication and pro-social behavior. Int J Contemp Hosp Manag 19(4):328-334

25. Greenspan R (2003) Job seekers have choices. ClickZ Network (May 22)

26. Herriot P, Rothwell C (1981) Organizational choice and decision theory: effects of employers' literature and selection interview. J Occup Psychol 54:17-31

27. Hsu C, Lu H (2004) Why do people play on-line games? An extended TAM with social influences and flow experience. Inf Manag 41(7):853-868

28. Hsu CL, Lin JC (2008) Acceptance of blog usage: the roles of technology acceptance, social influence and knowledge sharing motivation. Inf Manag 45(1):65-74

29. Jaccard J, Turrusi R (2003) Interaction effects in multiple regression, 2nd edn. Sage University Press, Thousand Oaks, CA

30. Jarvenpaa SL, Tractinsky N, Saarinen L, Vitale M (2000) Consumer trust in an internet store: a cross-cultural validation. J Comp Mediated Commun 5(2):13-22

31. Jones K, Leonard LNK (2008) Trust in consumer-to-consumer electronic commerce. Inf Manag 45(2):88-95

32. Kambil A (2008) What is your Web 5.0 strategy? J Bus Strategy 29(6):56-58

33. Kolekofski KE, Heminger AR (2003) Beliefs and attitudes affecting intentions to share information in an organizational setting. Inf Manag 40(6):521-532

34. Komiak SXK, Benbasat I (2006) The effects of personalization and familiarity on trust in and adoption of recommendation agents. MIS Q 30(4):941-960

35. Koufaris M, Hampton-Sosa W (2004) The development of initial trust in an online company by new customers. Inf Manag 41(3):377-397

36. Kuan H, Bock G (2007) Trust transference in brick and click retailers: an investigation of the before-online-visit phase. Inf Manag 44(2):75-187

37. Larzelere RJ, Huston TL (1980) The dyadic trust scale: toward understanding interpersonal trust in close relationships. J Marriage Fam 42(3):595-604

38. Lee I (2005) The evolution of e-recruiting: a content analysis of Fortune 100 career websites. Int J E Comm Org 3(3):57-68

39. Lee DW, Kauffman RJ, Bergen ME (2009) Image effects and rational inattention in Internet-based selling. Int $\mathrm{J} \mathrm{E}$ Comm 13(4):127-165

40. Liker JK, Sindi AA (1997) User acceptance of expert systems: a test of the theory of reasoned action. J Eng Technol Manag 14(2):147-173

41. Lu HP, Lin JCC (2003) Predicting customer behavior in the market-space: a study of Rayport and Sviokla's framework. Inf Manag 40(1):1-10 
42. Maurer SD, Liu Y (2007) Developing effective e-recruiting websites: insights for managers from marketers. Bus Horiz 50(4):305-314

43. Mayer RC, Davis JH, Schoorman FD (1995) An integrative model of organizational trust. Acad Manage Rev 20(3):709-734

44. McKnight DH, Choudhury V, Kacmar C (2002) Developing and validating trust measures for e-commerce: an integrative typology. Inf Syst Res 13(3):334-359

45. McKnight DH, Cummings LL, Chervany NL (1998) Initial trust formation in new organizational relationships. Acad Manage Rev 23(3):473-490

46. Martin J (2006) Multiple intelligence theory, knowledge identification and trust. Knowl Manag Res Pract 4(3):207-215

47. Neubauer T, Stummer C (2010) Interactive selection of web services under multiple objectives. Inf Technol Manag 10(1): $25-41$

48. Ong CS, Lai JY, Wang YS (2004) Factors affecting engineers' acceptance of asynchronous e-learning systems in high-tech companies. Inf Manag 41(6):795-804

49. Parry E, Tyson S (2008) An analysis of the use and success of online recruitment methods in the UK. Hum Res Manage J 18(3):257-274

50. Pavlou PA, Dimoka A (2006) The nature and role of feedback text comments in online marketplaces: implications for trust building, price premiums and seller differentiation. Inf Syst Res 15(1):391-412

51. Pavlou PA, Fygenson M (2006) Understanding and predicting electronic commerce adoption: an extension of the theory of planned behavior. MIS Q 30(1):115-143

52. Rousseau DM, Sitkin SB, Burt RS, Camerer C (1998) Not so different after all: a cross discipline view of trust. Acad Manage $\operatorname{Rev} 23(3): 393-404$
53. Rynes SL (1991) Recruitment, job choice, and post-hire consequences: a call for new research directions. In: Dunnette MD, Hough LM (eds) Handbook of industrial, organizational psychology. Consulting Psychologists Press, Palo Alto, CA

54. Scharl A, Gebauer J, Bauer C (2001) Matching process requirements with information technology to assess the efficiency of web information systems. Inf Technol Manag 2(2):193-210

55. Schoorman D, Mayer R, Davis JH (2007) An integrative model of organizational trust: past, present, and future. Acad Manage Rev 32(2):344-354

56. Serva MA, Fuller MA (2004) The effects of trustworthiness perceptions on the formation of initial trust: implications for MIS student teams. J Inf Syst Educ 15(4):383-395

57. Simons TL (1999) Behavioral integrity as a critical ingredient for transformational leadership. J Org Change Manage 12(2):89-104

58. Stewart KJ (2003) Trust transfer on the World Wide Web. Org Sci 14(1):5-17

59. Swan JE, Trawick IF, Silva DW (1985) How industrial salespeople gain customer trust. Ind Mark Manage 14(3):201-211

60. Tagliavini M, Ravarini A, Antonelli A (2001) An evaluation model for electronic commerce activities within SMEs. Inf Technol Manag 2(2):211-221

61. Venkatesh V (2000) Determinants of perceived ease of use: integrating perceived behavioral control, computer anxiety and enjoyment into the technology acceptance model. Inf Syst Res 11(4):342-365

62. Venkateseh V, Davis FD (2000) A theoretical extension of the technology acceptance model: four longitudinal field studies. Manage Sci 45(2):186-204

63. Wu LL, Chen EL (2005) An extension of trust and TAM model with TPB in the initial adoption of on-line tax: an empirical study. Int J Hum Comput Stud 62(6):784-808 